\title{
Identification of a retinoic acid-sensitive period during primary axis formation in Xenopus laevis
}

\author{
Hazel L. Sive, ${ }^{1,4}$ Bruce W. Draper, ${ }^{2}$ Richard M. Harland, ${ }^{3}$ and Harold Weintraub ${ }^{1}$ \\ ${ }^{1}$ Department of Genetics, Fred Hutchinson Cancer Center, Seattle Washington 98104 USA; ${ }^{2}$ Department of Zoology, \\ University of Washington, Seattle, Washington 98195 USA; ${ }^{3}$ Department of Molecular Biology, University of California, \\ Berkeley, California 94720 USA
}

Retinoic acid (RA) is able to profoundly alter patterning of the primary body axis in embryos of the frog Xenopus laevis. The response to RA is dose-dependent, and leads to progressive truncation of the anteroposterior axis, with anterior structures most sensitive. Both mesodermal and ectodermal tissues are affected, and in vitro assays demonstrate that induced dorsal ectoderm is one direct target of RA. RA represses expression of anterior-specific genes and concomitantly induces expression of at least one posterior-specific gene. Resistance to RA is aquired gradually, during gastrula and early neurula stages, with posterior structures becoming resistant before anterior structures. These data demarcate in the embryo an anterior "domain," which may define the head rudiment and which transcends germ layers. RA can alter the axial pattern after its initial induction; thus, RA sensitivity defines a labile intermediate that occurs during axial patterning. These data suggest a possible role for $R A$ in normal axis formation.

[Key Words: Xenopus; retinoic acid; anterior gene expression; primary body axis]

Received March 5, 1990; revised version accepted March 26, 1990.

During amphibian embryogenesis, axial patterning occurs through a complex series of interrelated events. Soon after fertilization, a relative rotation of egg cytoplasm and cortex leads to the establishment of the future dorsoventral axis (for review, see Vincent and Gerhardt 1987; Gerhart et al. 1989|. This rotation is required for the induction, during later cleavage stages, of dorsal mesoderm (the future notochord and muscle). In the absence of a cortical rotation, only ventral mesoderm (future blood and mesenchyme) is induced (for review, see Smith 1989). The anteroposterior (A/P) axis becomes established during gastrulation. The primary events in this process appear to be the aquisition of $\mathrm{A} / \mathrm{P}$ polarity by the dorsal mesoderm (for review, see Gerhart and Keller 1986; Gerhart et al. 1989) and the concomitant induction of the dorsal ectoderm by the dorsal mesoderm (reviewed by Nieuwkoop et al. 1985; see also Dixon and Kintner 1989/. The ectoderm forms an $A / P$ array of tissues that eventually differentiate into brain, spinal cord, and various epidermal organs, including in frogs an anterior secretory organ, the cement gland (Perry and Waddington 1966; Lyerla and Pellizari 1974; Sive et al. 1989|. Previously, we showed that at least part of the $\mathrm{A} / \mathrm{P}$ axis in the frog Xenopus laevis is determined in a stepwise fashion. In particular, more posterior ectoderm (including presumptive neurectoderm) is transiently induced to a multipotential, anterior, "precement gland" state (Sive et al. 1989), although it does not differentiate

${ }^{4}$ Corresponding author. as cement gland. A similar sequence of events has been proposed for anterior and posterior neurectoderm (EyalGiladi 1954; Nieuwkoop et al. 1985).

Numerous reagents are able to perturb axial patterning and have been extremely useful in probing the phenomena and cell interactions normally involved in axis formation. For example, UV irradiation of fertilized eggs disrupts dorsoventral axis specification by preventing the cortical rotation required for this process (for review, see Vincent and Gerhardt 1987). Conversely, treatment of early blastulae with a pulse of $\mathrm{LiCl}$ results in "hyperdorsalized" embryos, in which excess anterior dorsal mesoderm is produced (Kao and Elinson 1988; for review, see Berridge et al. 1989|.

Acting through specific receptors (Giguere et al. 1987, Petkovich et al. 1987; Zelent et al. 1989) and cellular binding proteins (Maden et al. 1989; Perez-Castro et al. 1989), retinoic acid (RA) is able to alter expression of specific genes (e.g., see LaRosa and Gudas 1988; Hosler et al. 1989; Luscher et al. 1989/ and to perturb many developmental programs in vertebrates. These programs include skin formation, where RA may be necessary for normal epidermal layering (Kopan et al. 1987), and cranial neural crest development (Wedden et al. 1988; see also Balling et al. 1989). RA is able to perturb limb patterning and, because endogenous RA is distributed in an $A / P$ gradient (with a posterior maximum) in the limb bud, it appears to play a key role in limb development (for review, see Eichele 1989). Given these pleiotropic effects, we decided to examine whether RA alters axial 
patterning in embryos of the frog $X$. laevis. We report here that RA has profound effects on axis specification. In particular, RA prevents the formation of an array of anterior structures, including the brain, cement gland, and heart. Sensitivity to RA identifies a labile period that occurs during normal axial patterning and may reflect a role for RA in formation of the primary body axis.

\section{Results \\ $R A$ elicits a graded decrease in anterior axial tissue}

Whole late blastulae or early gastrulae were incubated in RA for variable periods of time or in variable concentration (not shown). A representative series of embryos is shown in Figure 1A. With increasing time of exposure to $1 \mu \mathrm{M}$ RA, there was a progressive deficiency of anterior structure in the resulting embryos (Table 1). It was clear that the ability of eyes to develop disappeared first, then that of cement gland and, finally, heart. The embryos also failed to elongate. The axial deficiency of these embryos could be scored on a previously described scale, the dorsoanterior index (DAI) (Table 1; Kao and Elinson 1988). The most severely affected RA-treated embryos (incubated in $10 \mu \mathrm{M} \mathrm{RA}$, continuously from fertilization) retained some axis, because although they lacked both otic vesicles and a heart, they generally had both a neural tube and somites. The severity of defects was a function both of the RA concentration (not shown) and the duration of incubation (Table 1). Below $0.1 \mu \mathrm{M}$ RA, only very slight or no axial defects were observed (not shown).

Perturbation of gastrulation has been correlated with alteration of axial patterning (Gerhart et al. 1989). In particular, a relative decrease in the amount of dorsal mesoderm may both slow gastrulation and result in anteriorly deficient embryos. At high RA concentrations, it was clear that although gastrulation began at the same time in both RA-treated embryos and controls, it was completed late in the RA-treated animals, because blastopore closure was delayed (Fig. 1B).

Additionally, at lower RA concentrations, by the end of gastrulation, the archenteron of RA-treated animals had not expanded and was very shallow compared to controls (Fig. 1C). This may have indicated a failure of the involuting, apically constricted endodermal "bottle" cells to respread during gastrulation and to allow archenteron expansion (see Gerhart and Keller 1986). These data indicated that RA perturbed gastrulation and may have reflected a decrease in the amount of (anterior) dorsal mesoderm. Preliminary results suggest that archenteron length and, therefore, the extent of dorsal mesodermal involution, is similar in control and RAtreated embryos. The quality of dorsal mesoderm in RA-treated animals is currently being examined.

$R A$ alters patterns of gene expression in intact embryos and in isolated dorsal ectoderm

RA-mediated defects were analyzed more precisely by use of molecular probes. The spectrum of genes exam- ined is detailed in Figure $2 \mathrm{~A}$ and represents an $\mathrm{A} / \mathrm{P}$ series, primarily expressed in ectodermal derivatives. In RA-treated embryos (lacking all head morphology but retaining a neural tube and somites), expression of the cement-gland-specific genes, $X C G-1$ and $X A G-1$, and the anterior ectodermal gene, $X A-1$ (Sive et al. 1989), was undetectable (Fig. 2B, lanes 1 and 2). As examined immunocytochemically, expression of the anterior neural marker, engrailed (Brivanlou and Harland 1989), was also absent after incubation in RA (Fig. 2C). In a series of less severely affected embryos (cyclopic, but retaining a cement gland), engrailed staining persisted in a band of similar width to controls but progressively nearer to the new anterior end of the embryos (Fig. 2C). In contrast, RA-treated embryos showed a two- to threefold increase in the expression of two other neural genes, XIF3 [expressed primarily in anterior central and peripheral nervous tissue (Sharpe et al. 1989)] and Xlhbox 6 [expressed in spinal cord neurons (Sharpe et al. 1987; Wright et al. 1990)] (Fig. 2B; lanes 1 and 2). Not all neural gene expression was affected by RA, because levels of $N$-CAM RNA were unaltered. Similarly, no change was observed in the levels of XHox-36 RNA [expressed in posterior ectoderm and mesoderm (Condie and Harland 1987)] or of an epidermal cytokeratin gene, E13, (J. Roberts, unpubl.; see Sive et al. 1989).

The perturbation of both anterior ectodermal (cement gland and neural) and mesodermal (heart) lineages by RA could have resulted from the abnormal development of just one of these lineages, which then affected the remainder through inductive interactions. Alternatively, RA could have acted directly on each affected tissue. We therefore asked whether dorsal ectoderm was a target for RA. By mid-gastrula, the dorsal ectoderm had been regionally induced for both cement gland (anteriorly) and neural tissue (more posteriorly), although no expression of terminal differentiation markers had occurred (Fig. 4B; Sive et al. 1989). When isolated dorsal ectoderm from mid-gastrula was incubated in neutral saline, high levels of all markers were later expressed (Fig. 2B, lane 3). However, when parallel explants were incubated in RA, the patterns of subsequent marker gene expression were altered in a manner identical to changes seen in whole RA-treated embryos (cf. lanes 2 and 4), indicating that RA could directly alter the fate of dorsal ectoderm that had been induced previously by mesoderm.

These data showed that anterior ectodermal gene expression was inhibited by RA and was accompanied by an increase in expression of two neural markers. Furthermore, because RA could elicit these effects directly on isolated, induced dorsal ectoderm, underlying mesoderm (for neural lineages) or pharyngeal endoderm (for cement gland; see Nieuwkoop et al. 1985) was not necessarily a mediator of the RA effects. Although the enhanced XlHbox 6 expression may have represented a compensatory increase in posterior neural development with anterior deficiency, the increased expression of $X I F 3$ was surprising, because of the anterior localization of this RNA (Sharpe et al. 1989). One possibility is that the persistent and increased XIF3 RNA reflects periph- 
eral nervous system hypertrophy, which may be controlled differently from central nervous system (CNS) development. In this regard, XIF3 may not behave as a typical marker of anterior ectodermal development. Furthermore, the absence of an alteration in XHox-36 levels indicated that not all posterior-specific genes were RAinducible.

\section{$R A$ acts as a modifier of primary ectoderm induction}

RA could clearly alter the fate of dorsal ectoderm after its initial induction had taken place and could, in this context, increase the expression of certain neural markers. We therefore addressed whether RA caused neural induction in in vitro assays. Neural tissue can be
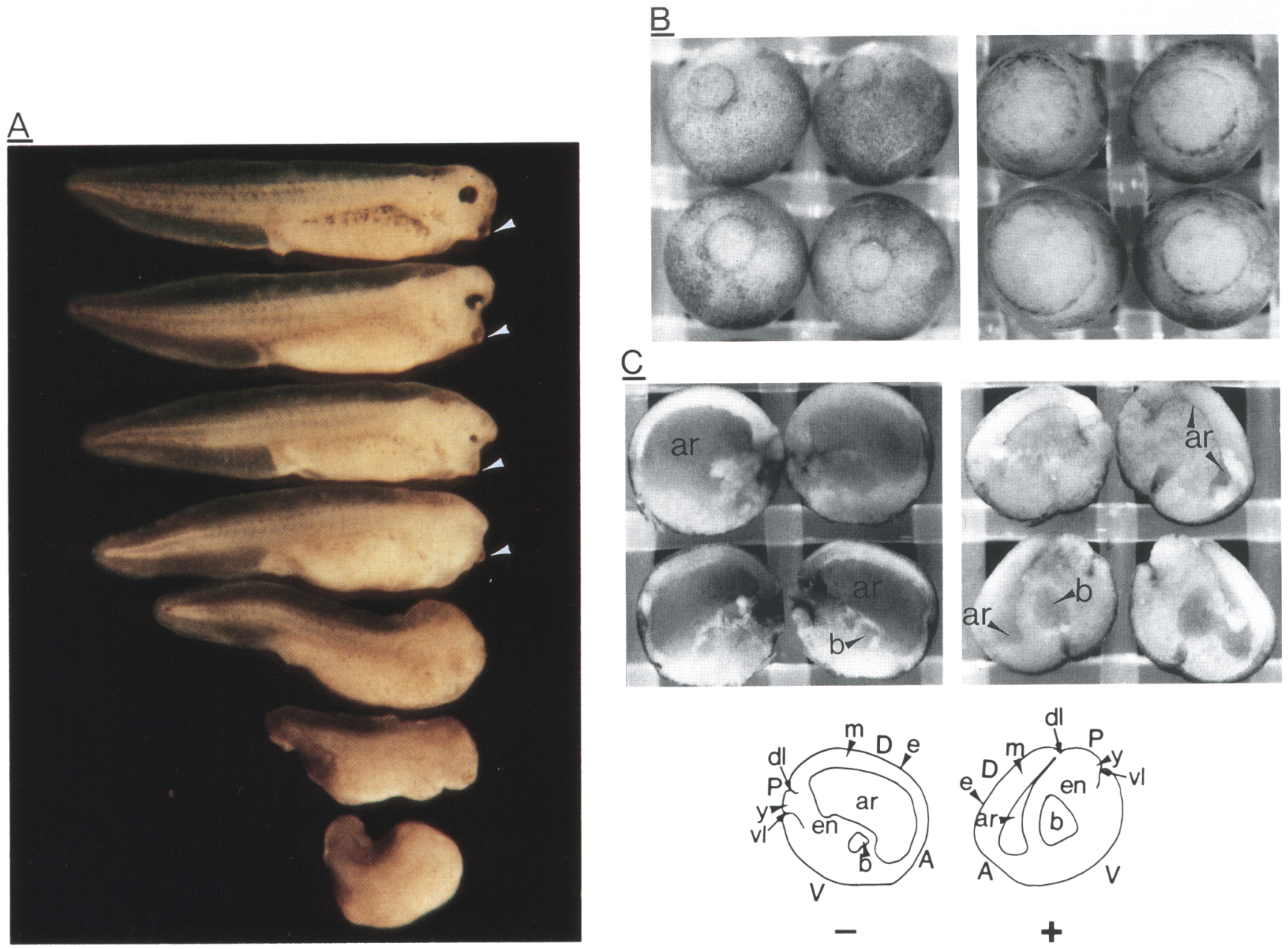

Figure 1. Morphology of RA-treated embryos. $(A \mid$ External appearance of embryos treated with $1 \mu \mathrm{M}$ RA for varying periods of time. RA was applied at stage 10 (Nieuwkoop and Faber 1956; late blastula) for $5 \mathrm{~min}$ to $2 \mathrm{hr}$ (see Table 1). Resulting embryos are shown at stage 35 (hatching). A normal embryo is shown at top. With increasing duration of RA treatment, embryos became cyclopic and then failed to develop any eye pigment. The ability to form a cement gland (arrowheads) persisted after eye formation had been lost. With longer RA application, the embryos became stunted. Melanophores were clearly formed in the RA-treated animals but failed to extend normal processes. In general, a neural tube and somites persisted even with extreme RA application (10 $\mu \mathrm{M}$ RA; continuous treatment from stage 1). Neural tube closure generally occurred in RA-treated Xenopus, unlike the case in mammalian embryos (e.g., see Sulik et al. 1988). From top to bottom, DAI values are 5.0, 4.0, 3.0, 2.5, 2.0, 1.0, and 1.0. Although the extent of axial patterning in the two bottom embryos is clearly different, these differences have not been examined carefully; therefore, equal DAI values are given. $(B)$ Changes in gastrulation rate caused by RA. Control embryos (left) and embryos incubated in $10 \mu \mathrm{M} \mathrm{RA}$ for $3 \mathrm{hr}$ from stage 10 (right) are shown at stage 12 (gastrula). Note that the blastopore is much larger in the RA-treated animals. As judged by initial appearance of the blastopore lip, gastrulation began at the same time in all animals (not shown). At lower RA concentrations ( $1 \mu \mathrm{M}$ ), retardation of blastopore closure was not always apparent. This retardation is somewhat different from that caused by UV-light treatment of fertilized eggs, where the blastopore initially forms late (see Gerhart et al. 1989). (C) Abnormal archenteron development caused by RA. Sagittal section of stage 15 (early neurula) normal embryos (left) and embryos incubated in I $\mu \mathrm{M}$ RA for $1 \mathrm{hr}$ from stage 10 . Camera lucida drawings of two embryos are shown below their respective photographs. (A) Anterior; (P) posterior; (D) dorsal; (V) ventral; (ar) archenteron; (b) blastocoel; (e) (dorsal) ectoderm; (m) (dorsal) mesoderm; (en) endoderm; (y) yolk plug of blastopore; (dl) dorsal lip of blastopore; (vl) ventral lip of blastopore; $(-)$ no $\mathrm{RA}_{;}|+|$incubated with RA. Note the failure of the archenteron to expand in the RA-treated animals. Additionally, in RA-treated embryos, the blastocoel did not decrease in size during gastrulation and neurulation as normal, but persisted into hatching stages. 
Table 1. Decrease in dorsoanterior index with increasing time of incubation in $R A$

\begin{tabular}{|c|c|c|c|c|c|}
\hline \multirow[b]{2}{*}{ Experiment } & \multirow{2}{*}{$\begin{array}{l}\text { Minutes in } \\
1 \mu M A^{2}\end{array}$} & \multicolumn{2}{|c|}{$\begin{array}{c}\text { Average } \\
\text { DAI }^{\mathrm{b}}\end{array}$} & \multicolumn{2}{|c|}{$\begin{array}{l}\text { Number of } \\
\text { embryos } \\
\text { scoredc }\end{array}$} \\
\hline & & 1 & 2 & $\bar{l}$ & 2 \\
\hline & 5 & 3.5 & 4.0 & 16 & 60 \\
\hline & 10 & 3.0 & 3.5 & 15 & 60 \\
\hline & 20 & 2.5 & 3.0 & 23 & 75 \\
\hline & 40 & 2.0 & 2.5 & 14 & 55 \\
\hline & 80 & 1.0 & 2.0 & 24 & 70 \\
\hline & 160 & 1.0 & 1.0 & 17 & 40 \\
\hline & 320 & ND & 1.0 & ND & 45 \\
\hline
\end{tabular}

(ND) Not determined.

ancubations were begun at stage 10 (Nieuwkoop and Faber 1956); see Materials and methods. Untreated embryos had a DAI of 5.0.

bDAI was scored according to Kao and Elinson (1988) and Scharf and Gerhart (1983), with modifications detailed as follows. DAI 5.0: normal; DAI 4.5: reduced forehead; DAI 4.0: reduced forehead, slightly cyclopic; DAI 3.5: cyclopic; DAI 3.0: extremely cyclopic, normal or reduced cement gland; DAI 2.5: no eye pigment, some cement gland present; DAI 2.0: no cement gland, beating heart and otic vesicle present; DAI 1.0: no beating heart, no otic vesicle. DAI values were within 1.0 units for each time point. Variation in DAI between experiments correlated with variation in the degree of embryo dejellying, and, presumably, with relative attenuation of the effective RA dose (H.L. Sive, unpubl.).

'Scored when controls reached stage 40 (Nieuwkoop and Faber $1956)$.

induced in explanted blastula ectoderm by conjugation with dorsal mesoderm. Additionally, induced but undifferentiated cement gland (precement gland) is a multipotential cell population that can be induced further by mesoderm into neural lineages at the expense of later cement gland differentiation (Sive et al. 1989). For the assays below, precement gland was produced by transient incubation of blastula ectoderm in $\mathrm{NH}_{4} \mathrm{Cl}$ (see Materials and methods; Picard 1975a,b). This treatment is a convenient and efficient way of inducing cement gland primordium without inducing neural tissue.

As shown in Figure 3, both cement-gland-specific (XCG-1 and XAG-1) and head-specific (XA-1) genes were strongly induced in ectoderm/mesoderm conjugates cultured without RA (lanes 2 and 3). Their expression was prevented by incubation of conjugates in RA (lane 4). In contrast, two neural markers, XIF3 (lanes 3 and 5) and $N-C A M$ (not shown) were induced to equivalent levels with or without RA. No expression of the neural markers tested (XIF3, N-CAM) was induced by incubation of blastula ectoderm alone in RA (lane 4).

Similarly, the fate of precement gland could be altered by conjugation with mesoderm. Thus, whereas high levels of XCG-1 and XAG-1 RNAs were present in differentiated cement gland (lane 6), very low levels were seen in precement gland/mesoderm conjugates (lane 7). Conversely, XIF3 (lane 7) and N-CAM (not shown) RNAs were expressed only in the conjugates. When pre- cement gland alone was incubated in $\mathrm{R} h$, all subsequent expression of anterior ectodermal markers was lost (lane 8 ), but no neural induction was effected. In the presence of RA, precement gland/mesoderm conjugates expressed XIF3 (lane 9) and N-CAM RNAs (not shown) but at very low levels.

These data demonstrated, first that RA was not able to induce neural tissue from either competent blastula ectoderm or from precement gland ectoderm. This was true even when these tissues were also incubated in cAMP (not shown), a reagent known to be synergistic with RA in tissue-culture systems (e.g., Strickland and Mahdavi 1978) and to augment amphibian neural induction in vitro (Otte et al. 1989). The fate of RA-inhibited precement gland is currently not known. Second, in the presence of RA, mesoderm could induce neural gene expression, either from blastula ectoderm or from a precement gland substrate. With precement gland as a substrate, however, very low levels of neural gene expression were seen. This may have been due partly to a toxic effect of RA on induced ectoderm, an observation supported by a decrease in the average explant size after RA treatment (not shown) and by a decline in levels of $E 13$ cytokeratin RNA (cf. lanes 7 and 9). When levels of XIF3 were normalized to $E 13$ levels, the ratio obtained in the RA-treated superinduced explants was still about threefold lower than controls, suggesting that in precement gland, RA may have preferentially inhibited the differentiation of both neural and cement gland precursor cells.

\section{$R A$ sensitivity is temporally limited}

Because RA could cause increased expression of certain neural-specific RNAs, it acted as an inducer. One feature of embryonic inducers is the limited temporal period in which they can act. We therefore asked whether sensitivity to RA was restricted to a particular period during ectoderm induction. In whole embryos, sensitivity to RA decreased during gastrula and early neurula stages (Table 2). Resistance to RA was aquired gradually, with restoration of the axial pattern in the reverse order to its loss. Thus, with RA application at mid-gastrula, embryos were able to elongate; with application at late gastrula (stage 12.5), a cement gland was subsequently formed; with application at early neurula (stage 14), some eye pigment later developed.

This limited sensitive period could be reproduced in vitro. Whereas induced dorsal ectoderm isolated from mid-gastrula went on to express high levels of both $X C G-1$ and $X A-1$ in culture, RA added at the time of explantation completely prevented accumulation of these RNAs (Fig. 4A, lanes 1-4). In contrast, dorsal ectoderm isolated from late gastrula (lanes 5-8) or early neurula (lanes 9-11) later accumulated XCG-1 and XA-1 to similar levels, with or without addition of RA. The aquisition of RA resistance was an intrinsic property of induced ectoderm, as isolated dorsal ectoderm from mid-gastrula that was incubated in neutral saline for various times before RA addition became RA resistant at 
$\underline{A}$

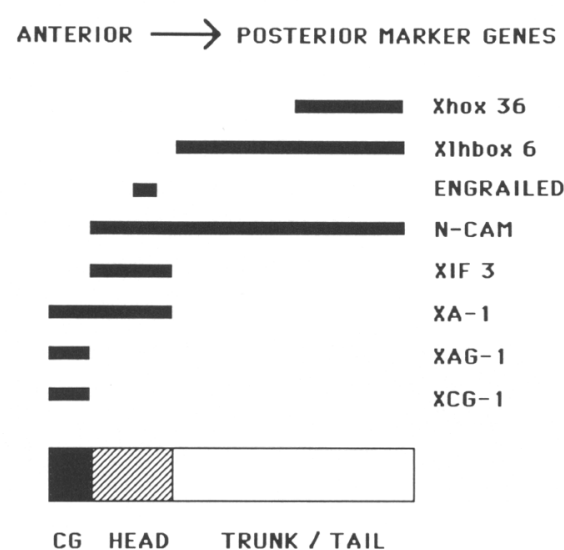

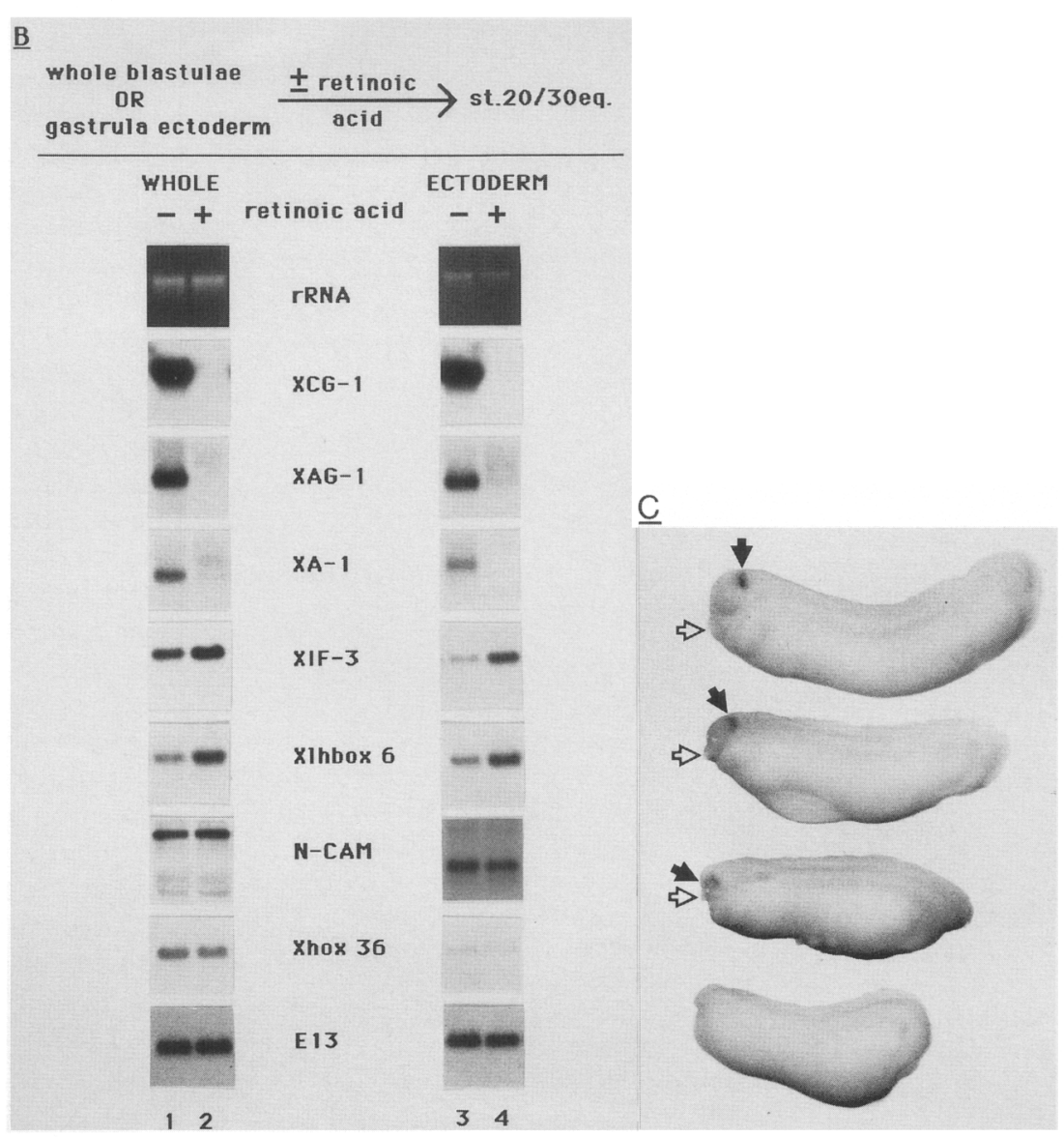

Figure 2. Alterations in gene expression caused by RA. $|A|$ Molecular probes used for analysis. A schematic plan of the embryonic axis and spatial distribution of markers is shown. Essentially all (except XHox-36) are ectoderm specific. XCG-1, XAG-1 and XA-1 have been described previously (Sive et al. 1989). XCG-1 is cement-gland-specific; $X A G-1$ is expressed predominantly in the cement gland, and at a low level $(<5 \%)$ elsewhere; $X A-1$ is expressed both in the cement gland and in remaining nonbrain head ectoderm. Its precise distribution has not been determined, and it may correspond to the gene XCG-2, described by Jamrich and Sato (1989). XIF3 is a peripherin gene, expressed in dorsal root ganglia and motor neurons anterior to the level of the hindbrain (Sharpe et al. 1989). Xlhbox 6 is a homeo-box-containing clone expressed in spinal cord neurons (Sharpe et al. 1987; Wright et al. 1990). N-CAM is the neural cell adhesion gene, expressed at the stages examined, in all parts of the nervous system (Balak et al. 1987; Kintner and Melton 1987). $X H o x-36$ is a homeo box-containing gene expressed in posterior ectoderm and mesoderm (Condie and Harland 1987). Specific expression of these genes first occurs in late gastrula (for XAG-1,XIF3 and N-CAM, very low levels of earlier or maternal expression are seen). E13, another marker used in these analyses, is an epidermal cytokeratin gene expressed in uninduced ectoderm after differentiation and without axial polarity (J. Roberts, unpubl.). Expression of this gene begins in late blastula (stage 10). (B) Northern analysis of gene expression in whole embryos or explants after RA treatment. Blastulae were incubated in $1 \mu \mathrm{M}$ RA for $2 \mathrm{hr}$, to give an average DAI of 2 (acephalic, but having a neural tube and somites; Kao and Elinson 1988). When control embryos reached stage 20 (late neurula; for Xlhbox 6 or XHox-36 analysis) or stage 30 hatching (for analysis of all other genes), RNA was prepared and analyzed by Northern hybridization. Alternately, induced dorsal ectoderm was isolated from mid-gastrula (see Materials and methods) and either cultured with or without $1 \mu \mathrm{M}$ RA until control embryos reached stage 20 or 30 . Northern analysis was then performed on total nucleic acid isolated from the explants. In all cases, embryo-equivalent amounts of RNA were analyzed; this essentially corresponded to mass equivalent amounts. The different pattern of $N$-CAM expression seen in lanes 1 or 2 compared to that in lanes 3 or 4 is a result of differences in gel electrophoresis prior to Northern blotting. An ethidium bromide-stained panel of $28 \mathrm{~S}$ rRNA is shown for comparison of relative loadings. (Lane 1) Control whole embryos; (lane 2) RA-treated whole embryos; (lane 3) control dorsal ectoderm; (lane 4): RA-treated dorsal ectoderm. (C) Expression of engrailed antigen in RA-treated embryos. Embryos were treated with $1 \mu \mathrm{M}$ RA for 5-20 min. Normal embryo is at top; a series of increasingly axially deficient embryos are shown below. Whole-mount immunocytochemistry was performed as described in Brivanlou and Harland (1989). Solid arrows indicate a band of engrailed-positive cells; open arrows indicate cement gland. Note the width of the engrailed band and its position relative to the cement gland.

approximately the same time as did whole embryos (see Fig. 4B|. The onset of RA resistance occurred before withdrawal of precement gland cells from the cell cycle (H.L. Sive, unpubl.) and coincided with the onset of $X C G-1$ and $X A-1$ expression (Sive et al. 1989).
The period of RA sensitivity and of precement gland plasticity are coincident

The ability of precement gland ectoderm to be "reprogrammed" by the dorsal mesoderm to more posterior 


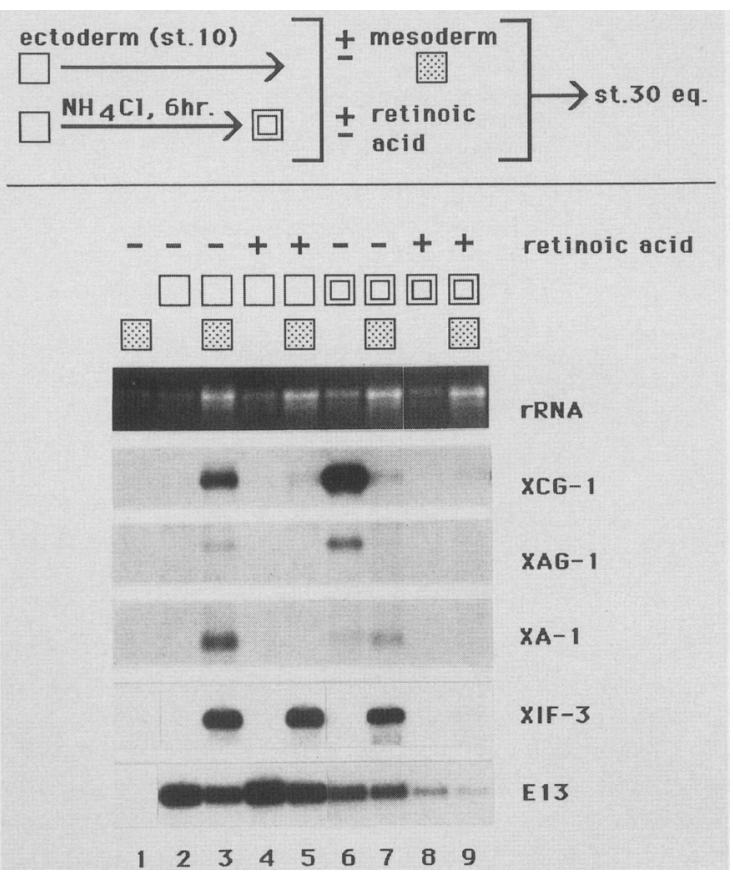

Figure 3. Analysis of RA effects on ectoderm induction in vitro. The general scheme of this experiment was as follows. Ectoderm was isolated from late blastula (stages 9-10). Dorsal mesoderm comprised a posterior piece from mid-gastrula (see Materials and methods). Freshly isolated ectoderm was incubated in neutral saline (see Materials and methods), with or without $1 \mu \mathrm{M}$ RA, either alone or as a conjugate with dorsal mesoderm. Alternately, precement gland was induced by treatment of stage 9-10 ectoderm for $6 \mathrm{hr}$ in $10 \mathrm{mM} \mathrm{NH}_{4} \mathrm{Cl}$ (see Materials and methods $\mid$. These explants were then incubated in neutral saline, with or without $1 \mu \mathrm{M} \mathrm{RA}$, alone or as conjugates with dorsal mesoderm. Explants were harvested at hatching equivalent stages. Northern analysis was performed for each of the genes shown [and for N-CAM (data not shown), which gave results identical to those obtained with XIF3]. Each lane represents a pool of 10 explants. An ethidium bromide-stained panel of $28 \mathrm{~S}$ rRNA is shown for comparison of relative loadings. The exposure for XIF3 was $\sim 10 \times$ longer than for the other genes. This experiment was performed six times, with similar results. Similar results have been obtained with in vivo-induced precement gland as substrate (H.L. Sive, unpubl.). (Lane 1) Dorsal mesoderm; (lane 2) ectoderm, no RA; (lane 3) ectoderm conjugated with mesoderm, no RA; (lane 4) ectoderm, $1 \mu \mathrm{M} \mathrm{RA}$; (lane 5) ectoderm conjugated with mesoderm, $1 \mu \mathrm{M} \mathrm{RA}$; (lane 6 ) $\mathrm{NH}_{4} \mathrm{Cl}$-induced ectoderm, no $\mathrm{RA}_{\text {; }}$ (lane 7) $\mathrm{NH}_{4} \mathrm{Cl}$-induced ectoderm, conjugated with mesoderm after $\mathrm{NH}_{4} \mathrm{Cl}$-treatment, no

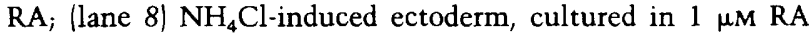
after induction; (lane 9) $\mathrm{NH}_{4} \mathrm{Cl}$-induced ectoderm, conjugated with mesoderm and cultured in $1 \mu \mathrm{M} \mathrm{RA}$ after $\mathrm{NH}_{4} \mathrm{Cl}$ treatment.

lineages may play two roles in $\mathrm{A} / \mathrm{P}$ axial patterning. The first is to determine the relative positions of cement gland and neurectoderm, and the second is to prolong the period during which ectoderm is competent for neural induction (Sive et al. 1989). Although the duration of this plasticity has not been determined, it clearly overlapped with the period of RA sensitivity (during gastrulation). Therefore, we asked more precisely how long the period of precement gland plasticity persisted and whether it coincided temporally with the period during which precement gland is sensitive to RA.

Presumptive cement gland was treated with RA immediately after induction, or $6 \mathrm{hr}$ later. At these same times, additional explants were further induced by conjugation with dorsal mesoderm (in the absence of RA). Figure $4 \mathrm{~B}$ shows that in explants treated with RA immediately after induction, expression of XCG-1 and XA-1 in the differentiated explants was completely inhibited (lanes 2 and 4). At this time, the ectodermal fate was labile, because after conjugation to mesoderm, subsequent $X C G-1$ RNA levels were very low relative to controls, whereas levels of $X A-1$ increased (lane 3$)(X A-1$ is predominantly expressed in ectoderm posterior to the cement gland; see Figs. 3 and 4A). Quite different results were obtained when similar protocols were followed 6 hr later. At this time, the precement gland ectoderm was RA resistant (cf. lanes 2 and 6 ). Additionally, this ectoderm was refractory to further induction by mesoderm, because similar XCG-1 and XA-1 levels were observed with or without additional induction (cf. lanes 2 and 5). These data indicated that RA resistance and the inability of precement gland to respond to mesodermal reprogramming were temporally correlated. Intermediate time points to those shown here confirmed this temporal correlation (H.L. Sive, unpubl.).

Table 2. Change in DAI with a pulse of RA applied at different times during development

\begin{tabular}{|c|c|c|c|c|c|c|}
\hline \multirow[b]{2}{*}{ Experiment } & \multicolumn{2}{|c|}{$\begin{array}{l}\text { Stage RA } \\
\text { applied }^{\mathbf{a}}\end{array}$} & \multicolumn{2}{|c|}{$\begin{array}{c}\text { Average } \\
\text { DAI }^{\mathrm{b}}\end{array}$} & \multicolumn{2}{|c|}{$\begin{array}{l}\text { Number of } \\
\text { embryos } \\
\text { scoredc }\end{array}$} \\
\hline & 1 & 2 & 1 & 2 & $\overline{1}$ & 2 \\
\hline & 9 & 9 & 1.0 & 2.0 & 21 & 70 \\
\hline & ND & 10 & $\mathrm{ND}$ & 2.0 & ND & 50 \\
\hline & 10.5 & ND & 1.0 & ND & 16 & ND \\
\hline & 11 & 11 & 2.0 & 2.0 & 32 & 50 \\
\hline & 11.5 & ND & 2.0 & ND & 35 & ND \\
\hline & ND & 12 & ND & 2.5 & ND & 65 \\
\hline & 12.5 & ND & 2.5 & ND & 18 & ND \\
\hline & ND & 13.5 & ND & 3.0 & ND & 50 \\
\hline & 15 & 15 & 4.5 & 4.5 & 30 & 40 \\
\hline
\end{tabular}

(ND) Not determined.

ane-hour pulse of $1 \mu \mathrm{M}$ RA (see Materials and methods). Stages are according to Nieuwkoop and Faber (1956). Stage 9: blastula; stages 10-10.5: early gastrula; stages 11-11.5: midgastrula; stages 12-12.5: late gastrula; stages 13.5-15: early neurula. A RA pulse applied at stage 1 (fertilized egg), stage 6 (32-cell stage), or stage 7 (mid-blastula) gave axially deficient embryos of similar DAI to the stage 9 pulse (not shown). This may be due to persistence of the RA, rather than its action at the time given; Durston et al. (1989) have reported that at lower RA concentrations, the most sensitive period begins at about stage 10 .

bDAI units are as in Table 1. For each experiment, the range in DAI was, at most, 0.5 units around mean. Variation in DAI between experiments correlated with variation in the degree of embryo dejellying, and presumably, the relative attenuation of RA dose (H.L. Sive, unpubl.).

cScored when controls reached stage 40 (Nieuwkoop and Faber 19561 . 

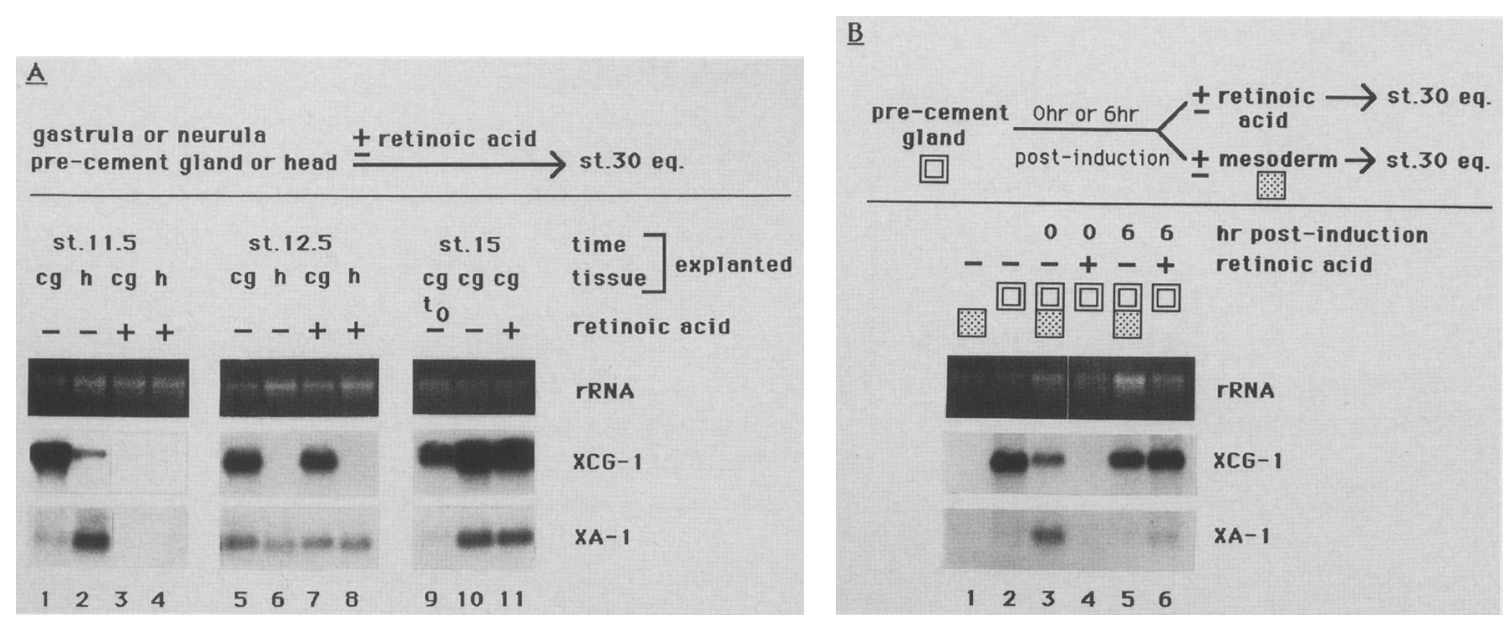

Figure 4. Temporal restriction of sensitivity to RA. (A) Aquisition of RA resistance for cement gland development. Anterior or more posterior dorsal ectoderm (not including the blastopore) was isolated from mid-gastrulae (stage 11.5) and allowed to differentiate in neutral saline, with or without the addition of $1 \mu \mathrm{M}$ RA. Additionally, tissue containing the cement gland primordium or remainder of the head was isolated from late gastrulae (stage 12.5) or early neurulae (stage 15) and then incubated in neutral saline, with or without inclusion of $1 \mu \mathrm{M}$ RA. Note that at stage 11.5 and 12.5 , the cement gland primordium is not morphologically apparent, and dissected regions were therefore approximate. Northern analysis was performed when control embryos reached hatching stages. Ten explants were loaded in each lane. An ethidium bromide-stained panel of 28S rRNA is shown for comparison of relative loadings. (Lane 1) Stage 11.5 anterior dorsal ectoderm (predominantly precement gland), no RA; (lane 2) stage 11.5 posterior dorsal ectoderm (head primordium, also including some presumptive posterior neural plate; see Fig. 2B), no RA; (lane 3) stage 11.5 anterior dorsal ectoderm, $1 \mu \mathrm{M}$

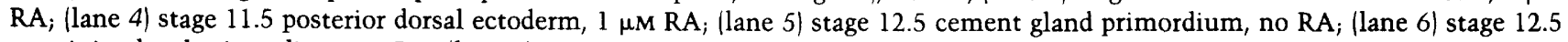
remaining head primordium, no $\mathrm{RA}_{\text {; }}$ (lane 7 ) stage 12.5 cement gland primordium, $1 \mu \mathrm{M} \mathrm{RA}_{\text {; }}$ (lane 8 ) remaining head primordium, 1 $\mu \mathrm{M} \mathrm{RA}$; (lane 9) stage 15 cement gland primordium, harvested at the time of explantation ( $\left.t_{0}\right)$; (lane 10) stage 15 cement gland primordium, no RA; (lane 11) stage 15 cement gland primordium, $1 \mu \mathrm{M}$ RA. (B) Correlation of RA sensitivity and plasticity of precement gland ectoderm. Ectoderm was isolated from late blastulae (stage 9), and presumptive cement gland was induced by a 6-hr incubation in $10 \mathrm{~m} \mathrm{M} \mathrm{NH}_{4} \mathrm{Cl}$ (see Materials and methods). Immediately after induction, precement gland was either conjugated with mid-gastrula dorsal mesoderm or incubated in $1 \mu \mathrm{M}$ RA. A similar protocol was followed $6 \mathrm{hr}$ later, with precement gland that had been incubated in neutral saline since the end of the $\mathrm{NH}_{4} \mathrm{Cl}$ induction. Explants were harvested at hatching equivalent stages and analyzed by Northern hybridization for the markers shown. Note the relative ratio of XCG-1 to XA-1; XCG-1 is expressed only in the cement gland, $X A-1$ is expressed predominantly in ectoderm posterior to the cement gland (see also Fig. 4A). An ethidium bromidestained panel of $28 \mathrm{~S}$ rRNA is shown for comparison of relative loadings. (Lane 1) Dorsal mesoderm; (lane 2) precement gland, no RA; (lane 3) precement gland conjugated with dorsal mesoderm immediately after induction, no RA; (lane 4) precement gland, incubated in $1 \mu \mathrm{M}$ RA immediately after induction; (lane 5) precement gland, conjugated with dorsal mesoderm $6 \mathrm{hr}$ after induction, no RA; (lane 6) precement gland, incubated in $1 \mu \mathrm{M}$ RA $6 \mathrm{hr}$ after induction.

\section{Discussion}

Here, we report the finding that RA is able to profoundly alter patterning of the primary body axis during $X$. laevis embryogenesis. This observation has been made independently by Durston et al. (1989; see also Mitrani and Shimoni 1989). Our data make two new and important points: (1) In the early embryo there appears to be a RAsensitive anterior "domain" that transcends germ layers and includes both ectoderm and mesoderm; (2) after its initial induction, the $\mathrm{A} / \mathrm{P}$ axial rudiment progresses through a period when its determination is labile and can be perturbed by RA. This lability may be requisite for subsequent subdivision of the embryonic axes.

\section{$R A$ alters determination of both anterior ectodermal and mesodermal derivatives}

When RA was applied to blastula- or gastrula-stage embryos, the resulting $\mathrm{A} / \mathrm{P}$ axis was truncated, with loss of both anterior ectodermal and mesodermal derivatives.
The posterior extent of truncation extended at least into the hindbrain. These data suggested that the embryo may include an anterior regional field, or domain, demarcated by its sensitivity to RA, which is perhaps set aside as the head rudiment (see below). Recently, Sundin et al. (1990) have shown that expression of a homeo boxcontaining gene, Ghox-lab, is restricted to a region posterior to the presumptive hindbrain in gastrulating chick embryos, perhaps demarcating the posterior boundary of an anterior, RA-sensitive domain.

RA inhibited expression of a series of anterior-specific (neural and cement gland) ectodermal genes. Because whole embryos and isolated, induced dorsal ectoderm responded to RA in a qualitatively and quantitatively similar manner, one direct target of RA appeared to be the dorsal ectoderm, after its primary induction. Preliminary results indicate that protein synthesis is required for inhibition by RA of anterior-specific ectodermal gene expression (H.L. Sive, unpubl.), suggesting that these marker genes are not a direct target of RA. RA also inhibited development of at least one mesodermal lineage, 
the heart. This may have been a direct effect of RA on dorsal mesoderm or a consequence of abnormalities in other cell types that are required for heart induction /see Sater and Jacobson 1989). Experiments are currently in progress to address these alternatives. Interestingly, a teratogenic effect of RA on mesoderm differentiation has been reported in hamster and mouse embryos (e.g., see Marin-Padilla 1966).

A key question is what became of cells that would normally contribute to anterior tissue in RA-treated embryos? There are several possibilities: These cells may have died, they may have differentiated as some other cell type, or they may have failed to differentiate at all. Cell death has been proposed as a major cause of RAmediated spina bifida in mouse embryos (Sulik et al. 1988; Alles and Sulik 1990). Indeed, we often observed a decrease in size of precement gland explants after RA treatment, suggesting that some decrease in cell number had occurred in vitro. RA may have also altered cell lineage, because consistently, decreased anterior neurectodermal gene expression was accompanied by an increase in expression of two other neural markers [XIF3 (Sharpe et al. 1989) and Xlhbox 6 (Wright et al. 1990)]. Although the level of expression of these genes on a per cell basis was not determined, one inference was that the anterior deficit was compensated by an increase in posterior and perhaps peripheral neural differentiation. This alteration was dependent on previous ectoderm induction, because RA was not able to induce neural gene expression in naive ectoderm. It was not clear whether the change in gene expression represented an active recruitment of precursor cells into new lineages, a passive shunting into available avenues of cells whose normal differentiation pathways were blocked (see Cooke and Smith 1987), or simply a hyperproliferation of some neural lineages.

Where RA alters fate during primary axis formation, does it affect an $\mathrm{A} / \mathrm{P}$ homeotic transformation? In our studies, as the $\mathrm{A} / \mathrm{P}$ axis was progressively truncated, no increase in the number of cells expressing the engrailed antigen was observed at any point, indicating that RA does not effect homeotic transformation ubiquitously along the length of the $\mathrm{A} / \mathrm{P}$ axis. By morphological assay, however, Durston et al (1989) have reported an increase in hindbrain volume in anteriorly deficient, RA-treated Xenopus embryos. Additionally, Meijlink and coworkers (1989) have shown that RA is able to induce expression in primary cultures of mouse midbrain cells of the Hox-2.3 gene, which is normally expressed more posteriorly. These data indicate that RA may alter fate in different ways at different points along the $\mathrm{A} / \mathrm{P}$ axis.

\section{$R A$ sensitivity and progressive determination of the $A / P$ axis}

A major result of this study was that the response to RA was graded and that development of anterior structures was inhibited after shorter RA treatments [or at lower dose (data not shown)] than was development of more posterior structures. A second point was that sensitivity to RA was temporally restricted. As gastrulation and early neurulation proceeded, the $\mathrm{A} / \mathrm{P}$ axial plan gradually became RA resistant, with posterior structures becoming resistant before those anterior. What do these data indicate about normal axis formation? From previous studies, it appears that induction of anterior ectodermal lineages precedes more posterior induction. Initially, however, anterior induction is labile, and primary induced cells may be respecified to more posterior lineages (Eyal-Giladi 1954; Sive et al. 1989). As gastrulation proceeds, cells fated to contribute to the true anterior primordium become induced (Sive et al. 1989). Nieuwkoop et al. (1985) have proposed that A/P transformation of the neurectoderm is affected by a "caudalizing factor." RA may be such a factor (as has been suggested by Durston et al. 1989) because it increased the absolute levels of a posterior (spinocaudal) neural marker (Xlhbox 6). However, the RA response appears rather complicated because $\mathrm{A} / \mathrm{P}$ transformation is not general along the $\mathrm{A} / \mathrm{P}$ axis and because RA treatment may also alter mesodermal character.

A speculative scheme of primary $\mathrm{A} / \mathrm{P}$ axis formation can be drawn from the available data (and is diagrammed, for ectoderm, in Fig. 5). Initially, dorsal mesoderm may release some unidentified factor that (in a stepwise fashion/ may induce ectoderm to assume a spectrum of potential anterior fates. These fates may be altered by a second factor, perhaps $\mathrm{RA}$, to a set of more posterior lineages. For cells to become irreversibly committed to anterior fates, they would need to migrate away from the source of this second factor (see also Gerhart et al. 1989). The most anterior lineages would have to gain the greatest distance from this source and would take the longest time to aquire it. By immersing embryos in RA, one may effectively place this second factor continuously along the $\mathrm{A} / \mathrm{P}$ axis and may prevent the stable induction of sets of cells not normally exposed to a particular concentration in vivo. This model explains both the ability of RA to obliterate anterior induction, in a dose-dependent way, after the initial axial pattern has been laid down, and the sequential aquisition of RA resistance.

Ectoderm induction seems to be initiated by the dorsal mesoderm, which itself aquires $\mathrm{A} / \mathrm{P}$ regionality during gastrulation, initially by self-organization $\mathrm{SSu}$ zuki et al. 1984; Dale and Slack 1987; Gerhart et al. 1989). Perhaps this organization utilizes the same factors that direct regionalization of the ectoderm. The expression of many vertebrate homeo box genes, in cluding potentially RA-responsive genes (Sundin et al. 1990 ) in both mesoderm and ectoderm (e.g., see Condie and Harland 1987; Wright et al. 1989) may reflect a common mechanism of generating (or maintaining) $\mathrm{A} / \mathrm{P}$ positional information in both of these germ layers.

\section{A labile period during axial patterning}

$\mathrm{RA}$ is able to perturb axis formation after the $\mathrm{A} / \mathrm{P}$ axial rudiment has been specified into precement gland and neural primordia, but before terminal differentiation has 


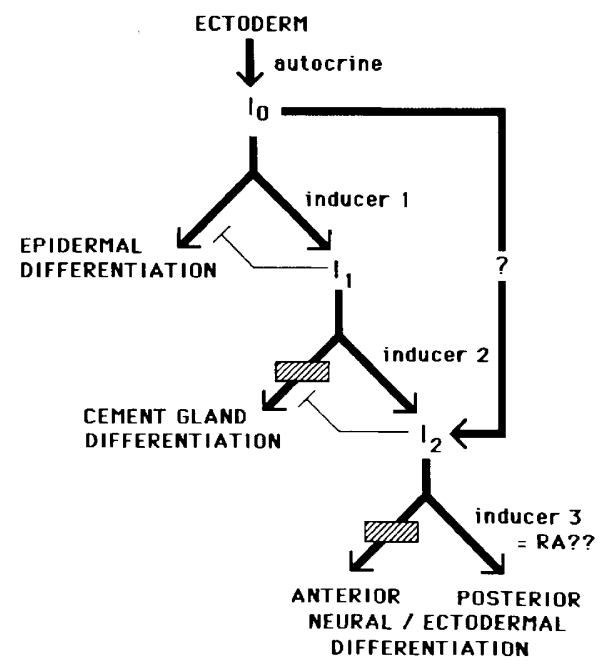

Figure 5. Hierarchy of ectoderm inductions and RA-sensitive points. This scheme is an extension of that presented in Sive et al. 1989. Ectoderm that is not subjected to an exogenous inducer becomes specified as epidermis (a state we have termed $\mathrm{I}_{0}$ ) (Jones and Woodland 1987; Sargent et al. 1986). I $\mathrm{I}_{0}$ cells are (transiently) a substrate for induction by dorsal mesoderm, upon which suppression of subsequent epidermal differentiation takes place (Jamrich et al. 1987; Sive et al. 1989). This induction can give rise to a population of ectodermal cells, termed $I_{1}$, which, if allowed to differentiate, will develop into cement gland. However, $I_{1}$ cells are a substrate for further induction by mesoderm, upon which suppression of subsequent cement gland differentiation occurs (Sive et al. 1989). This induction gives rise to a population of cells termed $\mathrm{I}_{2}$, which includes neural and other ectodermal precursor cells [e.g., most of the cells that express $X A-1$ (Fig. 4B)]. The identities of inducers 1 and 2 are not known, but a working model is that they are the same and that precement gland arises from a lower dose than does preneural tissue. RA inhibits cement gland and anterior neural differentiation by acting subsequent to production of $I_{1}$ and $\mathrm{I}_{2}$. Because at least some cells capable of responding to mesoderm remain in the RA-treated $I_{1}$ population, it seems that RA acts subsequent to the bifurcation of this population into precement gland and preneural cells. It is not clear whether RA is an active inducer of posterior and perhaps peripheral neural lineages or whether, after inhibition of cement gland and other anterior pathways, a passive shunt of induced precursor cells into other lineages occurs (see Discussion). It is also not clear whether passage through $I_{1}$ is obligate for neural induction. Cross-hatched boxes represent inhibition by retinoic acid.

occurred. RA sensitivity therefore defines a period when the anterior axial pattern is labile. Strikingly, the aquisition of RA resistance coincided with the end of a period during which precement gland ectoderm can be reprogrammed by dorsal mesoderm to more posterior lineages. Although RA alone did not effect precement gland respecification, it may be one component of this pathway. In this case, loss of some part of the RA response network, such as a receptor or a cellular binding protein, may mediate both RA resistance and loss of anterior plasticity.

The limited temporal sensitivity to RA indicates that for this step in axial patterning, a labile inductive event(s) is followed by its consolidation. Earlier steps in amphibian axial patterning (including dorsoventral axis formation and mesoderm induction) also progress through labile periods after they have initially occurred (see Gerhart et al. 1989; H.L. Sive, in prep.). This lability implies that active maintenance of inductions is required until irreversible committment to a particular set of lineages occurs. A similar requirement may be present during Drosophila axis formation, where various genes, including polycomb (Weeden et al. 1986) and extra sex combs (Struhl and Akam 1985), may maintain the appropriate distribution of Antennapedia and Bithorax gene products. In a teleological sense, it seems strange that initial inductive events can be altered so easily. Perhaps this plasticity allows the extensive regulation that can occur during normal embryogenesis. Perhaps also, this lability allows later refinement of an initially crude axial pattern into more precise subdivisions (see Keynes and Lumsden 1990), in the same way that sensory organ formation in Drosophila proceeds through a labile prepattern controlled by the achaetescute complex, which is later refined by the "neurogenic" loci (Romani et al. 1989).

Unlike other reagents that perturb axis formation, RA may be an endogenous morphogen (for review, see Eichele 1989). Indeed, retinoids are present in early frog embryos (Durston et al. 1989). The recent demonstration that genes normally expressed in a craniocaudal sequence along the major body axis are expressed in sequence in the limb bud (Dolle et al. 1989) may highlight further similarity between limb and primary body axis specification and lends credence to the idea that RA may also play a role in primary axial patterning. Analysis of the distribution of RA, its receptors, and cellular binding proteins during this process may help to dissect some of the molecular mechanisms regulating vertebrate axial patterning.

\section{Materials and methods}

Growth and culture of embryos

Embryos were obtained from adult $X$. laevis, as described in Sive et al. (1989).

\section{Dissection and induction of ectoderm}

Dissections were performed as described in Sive et al. (1989). For induction experiments, "animal caps" were isolated from late blastulae (stage 9, Nieuwkoop and Faber 1956) or early gastrulae (stage 10). Dorsal mesoendoderm was dissected from mid-gastrulae (stage 11.5), where a posterior piece of tissue was taken, extending anteriorly from (but not including) the blastopore, to the anterior margin of the archenteron. This enabled removal of vegetal endoderm cells from the dorsal mesoendoderm. Ectoderm and mesoderm were held together briefly to allow adhesion and then cultured as appropriate.

To induce precement gland, animal caps were incubated in $10 \mathrm{mM} \mathrm{NH}_{4} \mathrm{Cl}$ (Picard 1975a) in Holtfreter's solution (see Sive et al. 1989) for $6 \mathrm{hr}$, until control embryos had reached about stage 11.5 (mid-gastrula). Explants were then washed extensively in $1 \times$ modified Barth's saline (see Sive et al. 1989) and treated as described in the text. The $\mathrm{NH}_{4} \mathrm{Cl}$ incubation allows induction of precement gland that is apparently identical to in 
vivo-induced tissue, without induction of neural tissue (Picard 1975b; Sive et al. 1989|. Alternately, in vivo-induced precement gland was dissected from stage 11.5 embryos, as the ectoderm overlying the anterior one-third of invaginated dorsal mesoendoderm. In this case, because the boundary between precement gland and preneural tissue is not apparent, some preneural tissue was generally also removed.

\section{RA treatment}

All trans-RA (Sigma) was maintained as a $0.1 \mathrm{M}$ stock in DMSO and stored at $-20^{\circ} \mathrm{C}$. Dilutions were made into culture media just before use. Because RA is extremely insoluble in aqueous solutions and clearly came out of solution upon dilution of the stock, the actual concentration to which the embryos or isolated tissues was exposed was probably lower than reported.

\section{Plasmids and inserts}

Inserts were obtained from pXCG-1, pXAG-1, pXA-1, E13, and $\mathrm{N}$-CAM, as described (Sive et al. 1989). An EcoRI-HindIII insert was obtained from each of the XIF3 (Sharpe et al. 1989) and Xlhbox 6 (Sharpe et al. 1987) plasmids. An EcoRI insert was isolated from the XHox-36 plasmid (Condie and Harland 1987).

\section{Northern analysis}

RNA analysis was essentially as described in Sive et al. (1989). In some cases, total RNA was prepared from explants by lysis in urea lysis buffer [ $7 \mathrm{M}$ urea, $1 \times$ MOPS (Sigma), 0.5\% SDS], phenol extraction, and ethanol precipitation. Probes were prepared by random priming of isolated inserts.

\section{Fixation}

For sectioning, embryos were fixed in $4 \%$ paraformaldehyde, rinsed in $50 \%$ ethanol, and stored in $70 \%$ ethanol at $4{ }^{\circ} \mathrm{C}$.

\section{Immunocytochemistry}

Fixation and staining were performed as described in Brivanlou and Harland (1989).

\section{Acknowledgments}

We thank Eddie De Robertis, Doug Melton, Jim Roberts, and Colin Sharpe for plasmids, Eddie de Robertis and Chris Wright for communication of results prior to publication, and John Gerhart and Tabitha Doniach for helpful discussion. Thanks go to Jim Priess, Mark Groudine, and members of the Weintraub lab for thorough criticism of the manuscript and to Pei Feng Cheng for help with embryo preparation. H.L.S. continues to be indebted to A.B.L. and R.P.M. for encouragement. This work was supported by an American Cancer Society postdoctoral fellowship and a National Institutes of Health (NIH) Molecular Training Program in Cancer Research grant to H.L.S. and grants from the NIH to H.W. and to R.M.H.

\section{References}

Alles, A.J. and K.K. Sulik. 1990. Retinoic acid-induced spina bifida: Evidence for a pathogenetic mechanism. Development 108: $73-82$.

Balak, K., M. Jacobson, J. Sunshine, and U. Rutishauser. 1987. Neural cell adhesion molecule expression in Xenopus embryos. Dev. Biol. 119: 540-550.
Balling, R., G. Mutter, P. Gruss, and M. Kessel. 1989. Craniofacial abnormalities induced by ectopic expression of the homeobox gene Hoxl.1 in transgenic mice. Cell 58: 337-347.

Berridge, M.J., C.P. Downes, and M.R. Hanly. 1989. Neural and developmental actions of lithium: A unifying hypothesis. Cell 59: 411-419.

Brivanlou, A.H. and R.M. Harland. 1989. Expression of an engrailed-related protein in the anterior neural ectoderm of early Xenopus embryos. Development 106: 611-617.

Condie, B.G. and R.M. Harland. 1987. Posterior expression of a homeobox gene in early Xenopus embryos. Development 101: 93-105.

Cooke, J. and J.C. Smith. 1987. The mid-blastula cell cycle transition and the character of mesoderm in UV-induced nonaxial Xenopus development. Development 99: 197-210.

Dale, L. and J.M.W. Slack. 1987. Regional specification within the mesoderm of early embryos of Xenopus laevis. Development 100: 279-295.

Dixon, J.E. and C.R. Kintner. 1989. Cellular contacts required for neural induction in Xenopus embryos: Evidence for two signals. Development 106: 749-758.

Dolle, P., J. Izpisua-Belmonte, H. Falkenstein, A. Renucci, and D. Duboule. 1989. Coordinate expression of the murine Hox-5 complex homeobox-containing genes during limb pattern formation. Nature 342: 767-772.

Durston, A.J., J.P.M. Timmermans, W.J. Hage, H.F.J. Hendriks, N.J. de Vries, M. Heideveld, and P.D. Nieuwkoop. 1989. Retinoic acid causes an anteroposterior transformation in the developing central nervous system. Nature 340: 140-144.

Eichele, G. 1989. Retinoids and vertebrate limb pattern formation. Trends Genet. 5: 246-251.

Eyal-Giladi, H. 1954. Dynamic aspects of neural induction in amphibia. Arch. Biol. 65: 179-259.

Gerhart, J. and R. Keller. 1986. Region-specific cell activities in amphibian gastrulation. Annu. Rev. Cell Biol. 2: 201-229.

Gerhart, J.C., M. Danilchick, T. Doniach, S. Roberts, B. Rowning, and R. Stewart. 1989. Cortical rotation of the Xenopus egg: Consequences for the anteroposterior pattern of embryonic development. Development 107: 37-52.

Giguere, V., E.S. Ong, P. Segui, and R.M. Evans. 1987. Identification of a receptor for the morphogen retinoic acid. Nature 330: 624-629.

Hosler, B.A., G.J. LaRosa, J.F. Grippo, and L.J. Gudas. 1989. Expression of REX-1, a gene containing Zinc fingers motifs, is rapidly reduced by retinoic acid in $\mathrm{F} 9$ teratocarcinoma cells. Mol. Cell. Biol. 9: 5623-5629.

Jamrich, M. and C. Sato. 1989. Differential gene expression in the anterior neural plate during gastrulation of Xenopus laevis. Development 105: 779-786.

Jamrich, M., T.D. Sargent, and I.B. Dawid. 1987. Cell-type specific expression of epidermal cytokeratin genes during gastrulation of Xenopus laevis. Genes Dev. 1: 124-132.

Jones, E.A. and H.R. Woodland. 1986. Development of the ectoderm in Xenopus: Tissue specification and the role of cell association and division. Cell 44: 345-355.

Kao, K.R. and R.P. Elinson. 1988. The entire mesodermal mantle behaves as Spemann's organizer in dorsoanterior enhanced Xenopus laevis embryos. Dev. Biol. 127: 64-77.

Keynes, R. and A. Lumsden. 1990. Segmentation and the origin of regional diversity in the vertebrate central nervous system. Neuron 2: 1-9.

Kintner, C.R. and D.A. Melton. 1987. Expression of Xenopus N-CAM RNA in ectoderm is an early response to neural induction. Development 99: 311-325.

Kopan, R., G. Traska, and E. Fuchs. 1987. Retinoids as important regulators of terminal differentiation: Examining ker- 
atin expression in individual epidermal cells at various stages of keratinization. I. Cell Biol. 105: 427-440.

LaRosa, G.J. and L.J. Gudas. 1988. Early retinoic acid-induced F9 teratocarcinoma stem cell gene ERA-1: Alternate splicing creates transcripts for a homeobox-containing protein and one lacking the homeobox. Mol. Cell Biol. 8: 3906-3917.

Luscher, B., P.J. Mitchell, T. Williams, and R. Tjian. 1989. Regulation of transcription factor AP-2 by the morphogen retinoic acid and by second messengers. Genes Dev. 3: 15071517.

Lyerla, T.A. and J.J. Pellizari. 1974. Histological development of the cement gland in Xenopus laevis: A light microscopic study. I. Morph. 141: 491-502.

Maden, M., D.E. Ong, D. Summerbell, F. Chytil, and E.A. Hirst. 1989. Cellular retinoic acid-binding protein and the role of retinoic acid in the development of the chick embryo. Dev. Biol. 135: 124-132.

Marin-Padilla, M. 1966. Mesodermal alterations induced by hypervitaminosis A. J. Embryol. Exp. Morphol. 15: 261-269.

Meijlink, F., L. de Laaf, P. Verrikzer, W. de Graaf, and J. Deschamps. 1989. Regulation of expression of the Hox 2.3 gene. In Cell to cell signals in mammalian development. (ed. S.W. de Laat), vol. H26, pp. 23-41. NATO ASI Series, SpringerVerlag, Berlin/Heidelberg.

Mitrani, E. and Y. Shimoni. 1989. Retinoic acid inhibits growth in agarose of early chick embryonic cells and may be involved in regulation of axis formation. Development 107: $275-280$.

Nieuwkoop, P.D. and J. Faber. 1956. Normal table of Xenopus laevis (Daudin). North-Holland Publishing Company, Amsterdam.

Nieuwkoop, P.D., A.G. Johnen, and B. Albers. 1985. The induction of the neural plate. In The epigenetic nature of early chordate development. pp. 150-162. Cambridge University Press, Cambridge.

Otte, A,P., P. van Run, M. Heideveld, R. van Driel, and A.J. Durston. 1989. Neural induction is mediated by cross talk between the protein kinase $\mathrm{C}$ and cyclic AMP pathways. Cell 58: 641-648.

Perez-Castro, A.V., L.E. Toth-Rogler, L. Wei, and M.C. NguyenHuu. 1989. Spatial and temporal expression of the cellular retinoic acid binding protein and the cellular retinol-binding protein during mouse embryogenesis. Proc. Natl. Acad. Sci. 86: $8813-8817$.

Perry, M.M. and C.H. Waddington. 1966. The ultrastructure of the cement gland in Xenopus laevis. J. Cell Sci. 1: 193-200.

Petkovich, M., N.J. Brand, A. Krust, and P. Chambon. 1987. A human retinoic acid receptor belongs to the family of nuclear receptors. Nature 330: 444-450.

Picard, J.J. 1975a. Xenopus laevis cement gland as an experimental model for embryonic differentiation. I. In vitro stimulation of differentiation by ammonium chloride. $/$. Embryol. Exp. Morphol. 33: 957-967.

. 1975b. The cement gland of Xenopus laevis as an experimental model for embryonic differentiation. III. Histochemical and ultrastructural studies on cement gland differentiated in vitro. Arch. Biol. 86: 129-138.

Romani, S., S. Campuzano, E.R. Macagno, and J. Modolell. 1989. Expression of achaete and schute genes in Drosophila imaginal discs and their function in sensory organ development. Genes Dev. 3: 997-1007.

Sargent, T.D., M. Jamrich, and I.B. Dawid. 1986. Cell interactions and the control of gene activity during early development of Xenopus laevis. Dev. Biol. 114: 238-246.

Sater, A.K. and A.G. Jacobson. 1989. The specification of heart mesoderm occurs during gastrulation in Xenopus laevis. De- velopment 105: 821-830.

Scharf, S.R. and J.C. Gerhart. 1983. Axis determination in eggs of Xenopus laevis: a critical period before first cleavage, identified by the common effects of cold, pressure and ultraviolet irradiation. Dev. Biol. 99: 75-87.

Sharpe, C.R., A. Fritz, E.M. de Robertis, and J.B. Gurdon. 1987. A homeobox-containing marker of posterior neural differentiation shows the importance of predetermination in neural induction. Cell 50: 749-758.

Sharpe, C.R., A. Pluck, and J.B. Gurdon. 1989. XIF3, a Xenopus peripherin gene, requires an inductive signal for enhanced expression in anterior neural tissue. Development 107: $701-714$.

Sive, H.L., K. Hattori, and H. Weintraub. 1989. Progressive determination during formation of the anteroposterior axis in Xenopus laevis. Cell 58: 171-180.

Smith, J.C. 1989. Mesoderm induction and mesoderm-inducing factors in early amphibian development. Development 105: $665-677$.

Strickland, S. and Mahdavi. 1978. The induction of differentiation in teratocarcinoma stem cells by retinoic acid. Cell 15: 393-403.

Struhl, G. and M. Akam. 1985. Altered distributions of Ultrabithorax transcripts in extra sex combs mutant embryos of Drosophila. EMBO /. 4: 3259-3264.

Sulik, K.K., C.S. Cook, and W.S. Webster. 1988. Teratogens and craniofacial malformations: Relationships to cell death. $D e$ velopment (suppl.) 103: 213-234.

Sundin, O.H., H.G. Busse, M.B. Rogers, L.J. Gudas, and G. Eichele. 1990. Region-specific expression in early chick and mouse embryos of Ghox-lab and Hox 1.6, vertebrate homeobox-containing genes related to Drosophila labial. Development 108: 47-58.

Suzuki, A.S., Y. Mifune, and T. Kaneda. 1984. Germ layer interactions in pattern formation of amphibian mesoderm during primary embryonic induction. Dev. Growth. Differ. 26: $81-$ 94.

Vincent, J., and J.C. Gerhart. 1987. Subcortical rotation in Xenopus eggs: An early step in embryonic axis specification. Dev. Biol. 123: 526-539.

Weeden, C., K. Harding, and M. Levine. 1986. Spatial expression of antennapedia and bithorax gene expression by the polycomb locus in Drosophila. Cell 44: 739-748.

Wedden, S.E., J.R. Ralphs, and C. Tickle. 1988. Pattern formation in the facial primordia. Development (suppl.) 103: 3140.

Wright, C.V.E., K.W.Y. Cho, G. Oliver, and E.M. de Robertis 1989. Vertebrate homeodomain proteins: Families of regionspecific transcription factors. Trends Biochem. Sci. 14: 5256.

Wright, C.V., E.A. Morita, D.J. Wilkin, and E.M. de Robertis. 1990. The Xlhbox 6 homeo protein, a marker of neural in duction in Xenopus, is expressed in proliferating neuroblasts. Development. (in press).

Zelent, A., A. Krust, M. Petrovich, and P. Chambon. 1989. Cloning of murine and retinoic acid receptors and a novel receptor predominantly expressed in skin. Nature 339: 714717. 


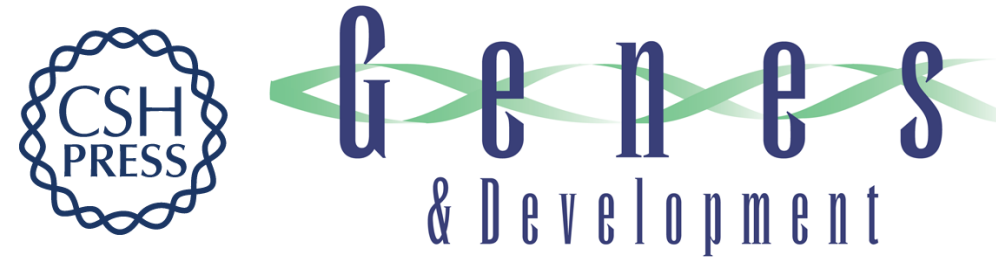

\section{Identification of a retinoic acid-sensitive period during primary axis formation in Xenopus laevis.}

H L Sive, B W Draper, R M Harland, et al.

Genes Dev. 1990, 4:

Access the most recent version at doi:10.1101/gad.4.6.932

References This article cites 54 articles, 24 of which can be accessed free at:

http://genesdev.cshlp.org/content/4/6/932.full.html\#ref-list-1

License

Email Alerting

Service

Receive free email alerts when new articles cite this article - sign up in the box at the top right corner of the article or click here.

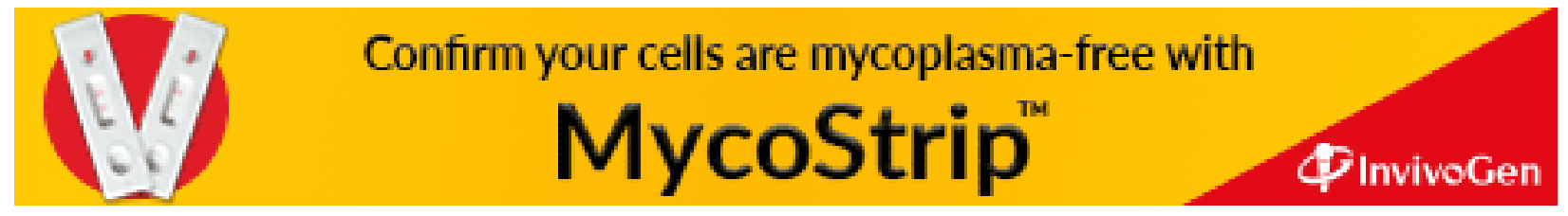

